\title{
Squandering in Ethic Economics: Consumer and Producer Behaviors Analysis
}

\author{
Bijan Bidabad \\ B.A., M.Sc., Ph.D., Post-Doc. \\ Professor \\ Economics and Chief Islamic Banking Advisor \\ Bank Melli, Iran \\ E-mail:bijan@bidabad.com
}

\begin{abstract}
Purpose: This paper investigates the effects of squandering on the economic behavior of consumer and firm. Moreover, we analyze consumer work-leisure behavior from the squandering viewpoint.

Findings: Commodity squandering creates no utility for the consumer. Just the "(real) consumption (usage)" satisfies the preference ordering rules of consumer behavior and the "squandered" commodities do not satisfy these rules. Definitionally, consumption is equal to "real usage" plus "squandered" commodities. Thence, the consumer will lose some parts of her utility because of squandering (because of lost resources). The amount of lost income resources due to squandering should be recompensated by more works to preserve the consumer's welfare constant. Squandering effects in total productivity, nonoptimal allocation of production factors, product wastage, and product decay are analyzed as less productivity and less supply of products due to squandering. According to this analysis, theoretically, it can be concluded that squandering will decrease the leisure and its corresponding utility of human being.

Social implications: If the ethic economics' doctrine affects the consumption pattern, this process will moderate consumption. Otherwise, the society will move toward exploiting all of her capital to: "just produce-just consume". The latter will be intensified by knowledge-based economic progress.
\end{abstract}

Keywords: Consumer theory, Firm behavior, Squandering, Ethic economics, Welfare economics, entertainment

JEL: DII, D2I, ZI2, DI9, D24

\section{Introduction}

Squandering is one of the important topics in ethic economics. Squandering Esr'af in Arabic grammar comes from the infinitive verb-form of Efal with the root of Sarafa) means "exceeding the limits of equilibrium (moderation)" and this passing is meant in exceeding sense and not in dismissing to. Ragheb Esfahani ${ }^{\mathrm{I}}$ (a Persian philosopher) defines Squandering (Sarafa) as "violating the limits in all aspects of human acts". Another definition and translation is given for squandering (Es 'raf) according to No.4 handwritten Qur'an², held in Astan-e-Ghods Razavi Library, which is mostly taken into consideration within this paper. This translation can be more justified with understandings of the teller, according to the era of the beginning of Islam in a historical view.

In this Quran, the word Squandered (Asrafa) is meant as "depraved" and Squandering (Israf) is translated as depraved-destroyed. The concept of destruction in economics has a very important weight. Destruction of resources is also one of the most important subjects in ethics economics. And this is because the main target in economics is to maximize the benefits of resources and if some part of numbered resources were not exploited correctly, therefore the optimization will be affected in all markets, and consequently, the economic behaviors will face this non-optimality as well. So it is obvious that the subject of squandering (Israf) is one of the most fundamental discussions in ethic economics that we treat herein.

Lots of verses in holy Qur'an explain Squandering as disrepute. In verses 7:31: "O children of Adam! take your adornment at every place of worship, and eat and drink, but be not prodigal. Lo! he loveth not the prodigals". In exegeses Bayan-o-Sa'adah it is

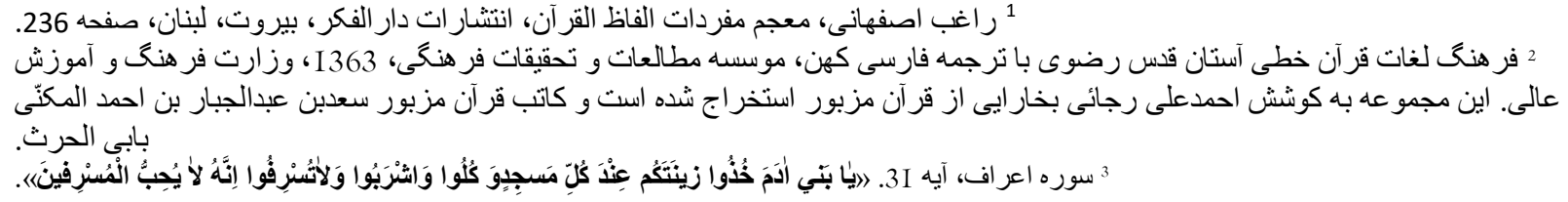


written: "O children of Adam take your adornment" - concerning each ornament for your beauty and body and its hygienic tools, beautiful and proper vestments, dressing of your hairs and barbs (with comb or with which it is decorated including perfumed oils) and approved acts and words from the other world, also the love of your families and good opinions, moral ethics and actions and correct revelations and inner (in heart) illuminations and spiritual observation, "at every place of worship" which appoints to any general condition for worship of God, meaning observance of the Master of Divine Authority (Caliph of God on the earth), all must be set aside. In these verses, adornments and place of worship are interpreted as mentioned. Everybody who wants to know about what is revealed to Innocent Imams can refer to Kaafi and Saafi or other sources. The part "and eat and drink" shows that ornaments, eating and drinking are allowed and are not in contradiction with payer or worship but even enables you to better worship and the generality of eating and drinking is obvious like an ornament. "But be not prodigal [extravagant- squanderer]" appoints the excess in decorating that will impeach you considering the truth (worship of God), because of business to earning it and earning the price to pay for it, protecting it and keeping it clean. It is also valid for eating and drinking and cleaning the foods and drinks because drinking more than thirst and eating more than hunger does harm to your health and spirit and make you ill and heavy for your tasks and jobs. "Lo! he loveth not the prodigals"; God does not love extravagant (squandering- exaggerating) people in whatever domain it could be. Because exaggerating (extravagance) is current in all acts and words and behaviors. As it is recited in response to the question: "is that possible to exaggerate in ablution? - yes, there is squandering (extravagancy-exaggeration- trespassing limits) even if you are doing ablution in a river". This is because allocating the power and members in any affair more than realizing the truth of that affair or more than earning its true effects, whatever that affair is, a religious obligation (Vajib) or advised one (Mustahab) or naturally allowed (Mubah) it is considered as exaggerating and squandering. And this verification is dependent on the case. But according to interpretation and heart witness, exaggerating in eating and drinking and vestment is in a way that the inner Satan (nafs) will take control over intellect $(A q I)$ and intellect become inattentive to its rule of controlling these desires. So squandering (exaggerating) is dominance (surpassing) of earning the desired and satanic pleasures over the intellect and the divine commandments."

From this point of view, the consistency of approbation of squandering or extravagance in all affairs can be understood, and within this discussion, we focus on an economic sense of eating and drinking, which are categorized in consumption. In another verses 6:I4I, it is said": "when it bears fruit eat of it and pay what is due (the zakat) of it upon the harvest day. But do not be wasteful; he does not love the wasteful". This is insinuation to dimensions of production in relation to squandering. There are also lots of other directives in Qur'an, recognizing the right of property for a person, but the obligation to respects the limits of equilibrium (moderation) in expending or consuming these resources in consumption and production in the meantime and blame violating these limits and qualifies it to "squandering".

Not only in the exegeses of Shiites and Sunnites to Quran and other references such as Shiites' Four-Books and Sunnites' SixBooks lot of recites and narration exist about the prohibition of Squandering but in analytic books the discussions of squandering is under attention so explaining all of them requires writing several books. Despite the fact that contemporary analytic economic books have qualified "squandering" as the main chapters of Islamic economics, but they do not proceed to the study of the economic behavior of consumer and producer theoretically. In the meantime, this subject from the point of view of Ethic economics has not developed yet. It is a primordial subject to be studied and readjusted and experienced.

\section{Consumer behavior and squandering}

According to consumer's behavior theory in microeconomics, this behavior is based upon the following assumptions: if consumer obtains more utility from A than B, we say A is preferable than B. This is principally the main assumption of behavior of the consumer according to his rational behavior, and it is also accepted in ethic economics because everything that is commanded by intellect is also commanded by Shariah. Therefore, for all possible choices of B and A, the consumer will prefer $\mathrm{A}$ to $\mathrm{B}$, or $\mathrm{B}$ to $\mathrm{A}$, or is indifferent. One of these preferences is correct. According to transitive rule, if the consumer prefers $\mathrm{A}$ to $\mathrm{B}$, and $\mathrm{B}$ to $\mathrm{C}$, he prefers A to C. According to this logic and ordinality of utility, consumer behavior theory has been founded in microeconomics.

In the subject of squandering in the ethic economy, in addition to the above assumption and logic, we are facing another subject which can be set forth in the framework of consumption behavior satiation assumption. All assumptions of utility function including strictly quasi-concave and other marginal assumptions about time and quantity of a commodity (not being an integer) and similar classic analysis are also assumed here.

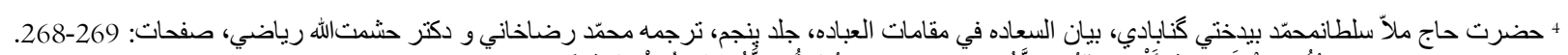

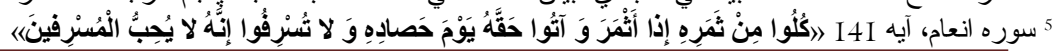
(c) (7) \&) Copright C CC-BY-NC 2019, CRIBEB | IJBM 
In the ordinary condition in consumer behavior theory in microeconomics, a consumer will maximize his utility function with the budget restraint. That is to say:

$$
\begin{array}{ll}
\text { Max: } & \mathrm{f}\left(\mathrm{q}_{1}, \mathrm{q}_{2}\right) \\
\text { S. to: } & y=\mathrm{p}_{1} \mathrm{q}_{1}+\mathrm{p}_{2} \mathrm{q}^{2}
\end{array}
$$

By formation of the Lagrange equation and obtaining necessary conditions, consumer's utility becomes maximized when the marginal utilities ratio is equal to price ratio:

$$
\frac{f_{1}}{f_{2}}=\frac{p_{1}}{p_{2}}
$$

Where $f_{1}$ and $f_{2}$ are first-order derivatives of utility function $f_{\text {regarding }} q_{1}$ and $q_{2}$. And $p_{1}$ and $p_{2}$ and yo are prices of $q_{1}$ and $q_{2}$ and consumer's income respectively. This equilibrium condition means that the rate of substitution the good is equal to the constant coefficient of Lagrange. The sufficient assumption needs that the bordered Hessian determinant be positive to satisfy the maximization. By solving the equation (I) and taking derivatives regarding $\mathrm{q}_{1}$ and $\mathrm{q}_{2}$ and Lagrange coefficient and solving equations for $\mathrm{q}_{1}$ and $\mathrm{q}_{2}$ we find the demand function:

$$
\begin{aligned}
& q_{1}=\phi_{1}\left(p_{1}, p_{2}, y\right) \\
& q_{2}=\phi_{2}\left(p_{1}, p_{2}, y\right)
\end{aligned}
$$

Where, changes of $\mathrm{q}_{1}$ to changes of $\mathrm{p}_{1}$ and changes of $\mathrm{q}_{2}$ to changes of $\mathrm{p}_{2}$ will be negative if other variables are constant (Ceteris Paribus) in ordinary conditions of (not Giffen) goods.

The consumer behavior for arranging her time for work and leisure in microeconomics can be obtained from a similar process. If his utility $(\mathrm{U})$ function is a function of leisure time $(\mathrm{L})$ and income $(y)$, we can write:

$\mathrm{U}=\mathrm{g}(\mathrm{L}, \mathrm{y})$

If the total available time for him is $\mathrm{T}$, and his working time is $\mathrm{W}$, and the wage rate is $\mathrm{r}$, his leisure time and income can be explained by the two following equations:

$\mathrm{L}=\mathrm{T}-\mathrm{W}$

$y=\mathrm{rW}$

By substituting in function (4), we will have:

$\mathrm{U}=\mathrm{g}(\mathrm{T}-\mathrm{W}, \mathrm{rW})$

We maximize this function by equating its derivative to zero:

$\frac{-d y}{d L}=\frac{g_{1}}{g_{2}}=r$

Where, $g_{1}$ and $g_{2}$ are partial derivatives of function $g$ with respect to $\mathrm{W}$ in composite function (6) for T-W and rW. The condition (7) shows consumer's equilibrium between work and leisure. If the second derivative of function U with respect to W is negative, the sufficient condition is met.

Neoclassic economics view to welfare is in consumption maximization; although, considering the relative preference of human being for work and leisure is theoretically acceptable from human being behavior, and people maximize their consumption and consider work and leisure, but practically, we see that they prefer consumption utility to leisure utility. That is to say; perhaps we can say people care about tangible materials (goods) more than spiritual utilities which are not tangible. This is because the five senses of human being feel materials better than spiritual meanings. This phenomenon changes human being to a work machine which does his best to produce material goods, while, a human being needs to proceed with spiritual products which are usually better achieved in leisure time. That is to say; it is necessary to leave some time for thinking and self-calculating, soulpurification, self-training, and spiritual and ethical affairs so that in this relation finds the purpose of her creation and steps forward towards spiritual elevation. The view of maximizing welfare through maximizing consumption means to increase $\mathrm{W}$ in function (8) more and more, and material consumption means body gains from bodily joys and ownership joys or obtaining and accumulating assets. While a human being cannot consume without limits. This is because, in spite of Neoclassic view in consumer's behavior in economics, which assumes non-satiation consumption, the consumer is satiationable which means he cannot consume more than a limited amount of goods and services. In other words, he has a limited capacity for consumption. If 
this fact is not true about all commodities, it is true about a group of commodities and services. For the other group which consumption is not limited, it is because of human being's thinking that she receives utility and satisfaction via more ownership of goods. The essential difference between these two groups of commodities, regardless of small differences, is the general classification of goods and services into two groups of durable and non-durables. Non- durables are consumers goods which do not last for a long time, and durables are possessory and some times last more than the life of their owners. The concept of contentedness in consumption, especially in the consumption of durable assets can be set forth as a chapter in ethic economics which we abstain from discussing it for the time being and will discuss it in another discussion.

Squandering is a kind of wasting resources, but squandering has a more general meaning than waste which includes overindulgence and excessive in all affairs, while the word "waste" does not have this variety of meaning. What we consider in squandering is the meaning of squandering and spoiling of resources, which makes sense about durable goods, but it makes more sense in non-durable goods. Since squandering causes corruption of good sources by destruction and abandonment because of "purchase greed" or "imitative consumption pattern", or "keeping up with Jones consumption pattern" or "consumptionism" ${ }^{6}$ or "habitual consumption", this term has more meaning of squandering rather than consuming, because sources have been obtained which are not used. In other words, in microeconomic theories, consumption is described as the purchase of good or actual demand, which means, purchasing of good is the same as consuming it. On the other hand, using simple words can better explain the purpose. Therefore, we write the following equation:

Consumption $=$ using + squandering

Its equation will be:

$q=q^{*}+q^{\sim}$

Where, $\mathrm{q}$ is the consumption considered by Neoclassic economists and $\mathrm{q}$ " and $\mathrm{q}$ are those parts of $\mathrm{q}$ which are used and wasted. Wasting may have any understanding of spoiling. For example, throwing away goods, their corruption, buying un-necessary goods, any kind of spoiling, going out of fashion, becoming useless, and... have this meaning.

Regarding the relation (8) or (9), we will again study consumer behavior for maximizing her utility. Rationally and logically, what is wasted does not create any utility for the consumer. In other words, if some or part of a commodity is spoiled or wasted or because of passing the time it is not useable, or becomes out of fashion, or not used for any reason, it has not been "used" and has not created any utility for the consumer. That is to say that only the usage of goods and services creates utility, rather than the purchase of it. Therefore, according to relation (8), only the usage of what is bought shows utility, not wasted and spoiled things.

We rewrite the utility function of the consumer by considering ( 9 ) and limiting the question to two commodities:

$$
\begin{array}{ll}
\max & f^{*}\left(q_{1}^{*}, q_{2}^{*}\right) \\
\text { s.to: } & y^{0}=p_{1}\left(q_{1}^{*}+q_{1}^{\tilde{}}\right)+p_{2}\left(q_{2}^{*}+q_{2}^{\tilde{2}}\right)
\end{array}
$$

Regarding the description mentioned about that wastes are without utility, do not enter the utility function, but they are in the budget line of the consumer. That is:

$$
\frac{\partial f^{*}}{\partial q_{1}^{\tilde{r}}}=\frac{\partial f^{*}}{\partial q_{2}^{\tilde{r}}}=0
$$

$\tilde{q_{2}}$ and $\tilde{q_{1}}$

We write the Lagrange equation for the problem (I0):

$$
V=f^{*}\left(q_{1}^{*}, q_{2}^{*}\right)+\lambda\left[y^{0}-p_{1}\left(q_{1}^{*}+q_{1}^{\sim}\right)-p_{2}\left(q_{2}^{*}+q_{2}^{\sim}\right)\right]
$$

The first condition for maximizing (I2) is:

\footnotetext{
${ }^{6}$ - Samuel Strauss (1870-1953) Critics on Consumptionism. The Atlantic Monthly, November 1924. He defines consumptionism as the science to force human being to more and more consumption of goods.
} 


$$
\begin{aligned}
& \frac{\partial V}{\partial q_{1}^{*}}=\frac{\partial f^{*}}{\partial q_{1}^{*}}-\lambda p_{1}=0 \\
& \frac{\partial V}{\partial q_{2}^{*}}=\frac{\partial f^{*}}{\partial q_{2}^{*}}-\lambda p_{2}=0 \\
& \frac{\partial V}{\partial \lambda}=y^{0}-p_{1}\left(q_{1}^{*}+q_{1}^{\tilde{}}\right)-p_{2}\left(q_{2}^{*}+q_{2}^{\tilde{2}}\right)=0
\end{aligned}
$$

In other words, the equilibrium condition for usage is the same as equilibrium condition for consumption, or:

$$
\frac{f_{1}^{*}}{f_{2}^{*}}=\frac{p_{1}}{p_{2}}
$$

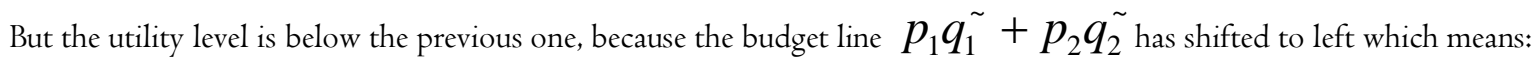

$$
\left(y-p_{1} q_{1}^{\tilde{1}}-p_{2} q_{2}^{\tilde{}}\right)=p_{1} q_{1}^{*}+p_{2} q_{2}^{*}
$$

In other words, the slope of utility curves has not been changed, but since a part of income has been wasted because of spoiling commodities, this line has shifted to the left and is tangent to utility curves with lower utility. In other words, in order to compensate for this reduction, we have to pay the amount of $p_{1} q_{1}^{\tilde{}}+p_{2} q_{2}^{\tilde{2}}$ to consumer until he reaches his consumption position before the waste. With additive utility function assumption we have:

$$
\begin{aligned}
& f\left(q_{1}, q_{2}\right)\left|=f\left(q_{1}^{*}, q_{2}^{*}\right)\right|+\left.f\left(q_{1}^{\sim}, q_{2}^{\sim}\right)\right|_{y^{*}} \\
& y=y^{*}+y^{\sim} \\
& p_{1} q_{1}+q_{2} q_{2}=p_{1}^{*} q_{1}^{*}+p_{2} q_{2}^{*}+p_{1} q_{1}^{\sim}+p_{2} q_{2}^{\sim}
\end{aligned}
$$

Therefore, regarding the utility received by the consumer, since usage creates utility, in the ordinary case of consumer theory, the consumer loses a part of his utility because of spoiling and wasting a part of his income. In order to keep his welfare, the wasted income because of spoil and waste, or $y^{\sim}$ should be earned through more work. So we study his behavior from work and leisure time point of view. As it was shown in equation (4), worker's utility is a function of income and leisure time variables. Now we write the second equation in this way:

$$
\begin{aligned}
& y=y^{*}+y^{\sim} \\
& r W=r W^{*}+r W^{\sim} \\
& y=r W^{*}+r W^{\sim}
\end{aligned}
$$

Where $y^{\sim}$ is the wasted amount of income for squandering and should be added for the one who has wasted this part of his income to keep his utility unchanged. $W^{\sim}$ is the work hours to earn this income. Therefore, we have:

$$
U=g(T-W, r W)=g\left[T-W^{*}-W^{\sim}, r\left(W^{*}+W^{\sim}\right)\right]
$$

Simply by comparing (6) and (20), we can understand that in order to have equilibrium in this case, the worker has to add $\mathrm{W}^{\sim}$ hours of work or decrease his leisure time to obtain enough income to compensate the wastes, while receiving no utility from his wastes. By equating partial derivatives of function $\mathrm{U}$ with respect to $\mathrm{W}^{*}$ and $\mathrm{W}^{\sim}$ to zero, we will have: 


$$
\frac{d U}{d W^{*}}=-g_{1}^{*}+g_{2}^{*} r=0 \quad \frac{d U}{d W^{\sim}}=-g_{1}^{\sim}+g_{2} \sim r=0
$$

Now we add the two equations:

$$
\frac{d U}{d W^{*}}+\frac{d U}{d W^{\sim}}=-\left(g_{1}^{*}+g_{1}^{\sim}\right)+\left(g_{2}^{*}+g_{2}^{\sim}\right) r
$$

This is the same equilibrium condition of (7). In other words:

$$
\frac{d U}{d W}=\frac{d U}{d W^{*}}+\frac{d U}{d W^{\sim}}
$$

Since $\mathrm{W}=\mathrm{T}-\mathrm{L}$, we can rewrite $(23)$ in this way:

$$
\frac{d U}{d W}=\frac{d U}{d W} \cdot \frac{d W}{d L}=-\frac{d U}{d L}
$$

Therefore:

$$
-\frac{d U}{d L}=\frac{d U}{d W^{*}}+\frac{d U}{d W^{\sim}}
$$

In other words, the consumer has to lose $d U / d W^{\sim}$ of his leisure time utility to buy wasted commodities.

It can be simply said that squandering causes waste of leisure time and its utility. This result does not violate the assumption of rationality of consumer and explains that since squandering causes a part of commodity sources -because of wrong shape of utility function and because of factors such as "purchasing greed", "imitation consumption", or "show off consumption" or "encouragement consumption" or "consumption oriented" or other similar things- become spoiled or become garbage, the consumer has to work more to compensate for the wasted materials and lose his leisure time to satisfy this consumption phenomenon. Actually, through this satisfaction, nothing has been used and he is imaginarily satisfied.

\section{Squandering and market demand}

We can clearly see the role of income in equations ( 3 ) of demand functions for goods. When $\mathrm{q}$ is the quantity demanded, and $\mathrm{p}$ is the price of the commodity in equations (3), the increase of $y$ shifts demand function to the right-hand side, and its decrease will shift it to the left-hand side. Now, if we divide income as in equation (19) into income for use ( $\left.y^{*}\right)$ and income for waste $\left(y^{\sim}\right)$, if by preventing waste, $y^{\sim}$ will increase; demand curve will move to left by this amount. This concept is correct in human being behavior as well as market demand, because market demand is the horizontal addition of individual demand functions. That is to say, if we show $i^{\text {th }}$ individual demand for $\mathrm{j}^{\text {th }}$ good as $\mathrm{D}_{\mathrm{i}, \text {, we can write: }}$

$$
D_{i j}=D_{i j}\left(p_{1}, \ldots \ldots, p_{m}, y_{i}\right)
$$

Where, $\mathrm{pI}, \ldots, \mathrm{p}_{\mathrm{m}}$ are prices of $\mathrm{m}$ commodities of the utility function of consumer $\mathrm{i}$ and $\mathrm{y}_{\mathrm{i}}$ is his income; then, market demand function will be as:

$$
D_{j}=\sum_{i=1}^{n} D_{i j}\left(p_{1}, \ldots \ldots . p_{m}, y_{i}\right)
$$

In which, $\mathrm{n}$ is the number of consumers in the market. By considering $\mathrm{y}^{*}$ and $\mathrm{y}^{\sim}$ we can rewrite the above equation as:

$$
D_{j}=\sum_{i=1}^{n} D_{i j}\left(p_{1}, \ldots \ldots, p_{m}, y_{i}^{*}+y_{i}^{\sim}\right)
$$

This relationship shows that the necessary income for compensating waste in individual demands will shift market demand, and will certainly affect the market demand. For example, for $y^{\sim}$ of all consumers, that is to say, necessary income for compensating wasted goods becomes zero, market demand equals to this amount and will shift to the left side. If other variables are unchanged, this shift will decrease the market price.

\section{Squandering and producer's behavior}

In spite of the fact that squandering is a well-known phenomenon in consumer's behavior, but it has a considerable justification in the producer's behavior. Usually, for different reasons, the production line has wastes in raw and intermediate materials or 
final goods, or has to produce goods with higher costs; which means it overuses manpower and other factors of production that all of them are cases of squandering and waste. In other words, by using a certain amount of factors of production in a production line, we have to produce a certain amount of goods which is equal to the maximum production capacity of the production line, but if we produce less, it means that we have practically wasted resources in production, and if we have produced low-quality goods, we have also practically wasted materials. Again, if goods are spoiled or wasted because of bad warehousing, we have again wasted and squandered. In other words, an outstanding amount of wastes in production is because of inefficient use of factors of production which will be studied here.

\section{The theory of the producer's behavior}

The production function of a firm shows the method of combination of factors of production $\left(\mathrm{X}_{\mathrm{I}}, \mathrm{X}_{2}, \ldots\right)$. In a simple form, production of $q$ is a function of:

$\mathrm{q}=\mathrm{f}\left(\mathrm{x}_{1}, \mathrm{x}_{2}\right)$

This is a continuous single-valued function for producing $Q$ with continuous first and second order derivatives for positive amounts of production and factors of production and is increasing in this range as an exactly ordinary concave function. At a fixed amount of the second factor of production $x^{0}{ }_{2}$, the average and marginal products of every factor of production $x_{1}$ will be equal with the ratio of total production to the total first factor of production and the ratio of changes of production to the changes of the first production factor. If we put total differential of function (29) equal to zero, rate of technical substitution (RTS) between factors of production at any fixed level of production will be:

$$
R T S=-\frac{d x_{2}}{d x_{1}}=\frac{f_{1}}{f_{2}}
$$

The optimum behavior of producer for maximizing profit is derived through maximizing the following function:

$$
\Pi=p f\left(x_{1}, x_{2}\right)-r_{1} x_{1}-r_{2} x_{2}-b
$$

Where, firm's profit $(\Pi$ ) is derived by maximizing the difference between sale income pq and cost (C). In which, $\mathrm{p}$ is the sale price and $r_{1}, r_{2}$ are prices of variable factors of production, and $b$ is the cost of constant factors of production. The necessary condition is obtained by equating first derivatives of this function to zero. To obtain the sufficient condition for maximizing (3I), the signs of main minors of its Hessian determinant should alternately be changed. If we solve the equations of necessary condition for $\mathrm{x}_{1}$ and $\mathrm{x}_{2}$, demand functions for factors of production are derived:

$$
\begin{aligned}
& x_{1}=\phi_{1}\left(r_{1}, r_{2}, p\right) \\
& x_{2}=\phi_{2}\left(r_{1}, r_{2}, p\right)
\end{aligned}
$$

The locus of points where we can get with minimum cost by combining factors of production defines the development path of the firm. In other words, the maximum production on different levels of costs has coordinates of different combining of factors of production whose locus is called the firm's development path and the firm always selects a combination of factors of production to keep on this path. We describe the path by the following function:

$$
g\left(x_{1}, x_{2}\right)=0
$$

The cost function of the firm is derived by simultaneously solving production function, cost line and firm's development path for C. In other words, we solve the below functions for C:

$$
\begin{aligned}
& q=f\left(x_{1}, x_{2}\right) \\
& c=r_{1} x_{1}+r_{2} x_{2}+b \\
& 0=g\left(x_{1}, x_{1}\right)
\end{aligned}
$$

The following relationship is derived, which is called the cost function:

$$
c=\phi\left(q, r_{1}, r_{2}\right)+b
$$

The production supply function of a firm in a perfectly competitive market for a commodity defines the amount of commodity production and is derived from the necessary condition for maximizing profit. The condition for maximizing profit is derived by equating price and marginal cost. In other words, the supply function of the firm $(S)$ in a perfectly competitive market is defined for the amounts of products with higher prices than average cost. 


\section{Squandering in production}

We can study squandering in production from different aspects. The following instances can be mentioned:

- Squandering in total productivity: that is, with a fixed amount of factors of production, produce less than maximum productivity condition.

- Squandering in a non-optimal combination of production factor (allocative inefficiency): which means that the combination of factors of production is not used in the process of production in an optimal way.

- Technological inefficiency: This means that the percentage of defective products or below standard is high.

- The spoil of products: because of bad warehousing, preserving, packing, or distribution of products.

\section{Squandering in total productivity}

One of the cases of squandering in production is squandering in total productivity. The increase in total productivity means to produce more goods with a fixed amount of factors of production. Consider the following function:

$$
q=A f\left(x_{1}, x_{2}\right)
$$

In which $A$ defines total productivity. If $A=I$, the production function will be similar to equation (29). Now consider two cases: one with efficient production and optimum use of resources, the other with low productivity and un-optimal use of resources. Certainly, in both cases, they use factors of production in the framework of optimization of production. To explain this cas e, we use the following relationship:

$$
A^{*}=A-A^{\sim}
$$

$\mathrm{A}^{*}$ is a multiple of total productivity which is practically carried out, and $\mathrm{A} \sim$ is related to that part of the production that because of inefficiency has practically no production. We call this part of production which is not taken into account "squandering in total productivity". By replacing (37) in (36), we will have:

$$
q=A^{*} f\left(x_{1}, x_{2}\right)+A^{\sim} f\left(x_{1}, x_{2}\right)
$$

In the right-hand side term, the produced production is $\mathrm{q}^{*}$ and unproduced production is $\mathrm{q}^{\sim}$. In other words:

$$
q=q^{*}+q^{\sim}
$$

Squandering in total productivity means to use resources or factors of production in excess of productions' needs $\left(\mathrm{q}^{\sim}\right)$. In other words, it is possible to calculate wasted materials in this way. If we solve the following equation for $\mathrm{C}$ :

$$
\begin{aligned}
& q=A^{*} f\left(x_{1}, x_{2}\right)+A^{\sim} f\left(x_{1}, x_{2}\right) \\
& 0=g\left(x_{1}, x_{2}\right) \\
& C=r_{1} x_{1}+r_{2} x_{2}+b
\end{aligned}
$$

We will have:

$$
C=\phi\left(q^{*}, r_{1}, r_{2}\right)+\phi\left(q^{\sim}, r_{1}, r_{2}\right)+b
$$

Which means that cost is made from two parts of production-used cost, and squandered costs. On the other hand, by using the above relation, we can obtain the demand for factors of production:

$$
\begin{aligned}
& x_{1}=x_{1}^{*}+x_{1}^{\sim} \\
& x_{2}=x_{2}^{*}+x_{2}^{\sim}
\end{aligned}
$$

In other words, on the basis of relationship (32) we will have:

$$
x_{1}=\phi_{1}^{*}\left(r_{1}, r_{2}, p\right)+\phi_{1}^{\sim}\left(r_{1}, r_{2}, p\right)
$$

$x_{2}=\phi_{2}^{*}\left(r_{1}, r_{2}, p\right)+\phi_{2}^{\sim}\left(r_{1}, r_{2}, p\right)$

$\phi_{1}^{\sim}$ and $\phi_{2}^{\sim}$ are squandering demands for factors of production which were equal to zero if total productivity were at maximum, but since there are waste and squandering, they are positive figures in the above relations. These positive figures of $\phi_{1}^{\sim}$ and $\phi_{2}^{\sim}$ practically cause the demand functions for factors of production to shift to the right side, causing increased use of factors of production and increase of the price of these factors, without increasing production. 
Squandering because of a non-optimal combination of factors of production

Another case of squandering is the non-optimal combination of factors of production. The microeconomic theory considers three general areas. One area is irrational production area in which marginal production of at least one factor of production is negative. Certainly, squandering in this area is very high. The negative productivity of a factor of production means overuse of that factor more than need, and its marginal use has caused production decrease. For example, if seeds are sprinkled more than need, the crop will decrease rather than increase. The other area is the rational production area. In this area, squandering is less, but because of non-optimum use of resources, production may not be at the maximum. The marginal productivities of the factors of production are positive in this area, but the combination of factors of production is not correct. If we optimize the combination of factors of production, this deficiency will be overcome.

Mathematically, maximum production behavior regarding cost constraint is obtained by maximizing the following Lagrange equation:

$$
V=f\left(x_{1}, x_{2}\right)+\mu\left(C^{0}-r_{1} x_{1}-r_{2} x_{2}-b\right)
$$

By equating derivatives of the above function with respect to $\mathrm{x}_{1}, \mathrm{x}_{2}, \mu$ to zero, we will have:

$$
\frac{f_{1}}{f_{2}}=\frac{r_{1}}{r_{2}}=R T S
$$

In other words, the technical rate of substitution is equal to the price ratio of factors of production. This point is the tangent of cost line $\mathrm{C}^{0}$ to the isoquant curve, which maximizes production regarding cost constraint. Certainly, any other combination of factors of production causes squandering of the factor, and as it was shown in (42) and (43), this has increased demand for factors of production by $x_{2}^{\sim}$ and $x_{1}^{\sim}$ without increasing production.

\section{Production damages}

Production damages usually occur for a variety of reasons including the damages caused by worker's negligence, inferior quality of raw material, machinery problems, and other problems which have different forms in industrial and traditional goods and services production lines, but all of them are considered here as production damages which lead to low-quality production. Since production damages are bulks, they have special uses, and other firms buy them for different uses, but since they have low qualities, will decrease the production yield. In short, we can generalize all the described effects of the decrease in total productivity for this subject as well. In other words, we conclude that the increase in production damages leads to a decrease in productivity, and it has similar effects. Therefore, the more is production damages, the more will be demand for factors of production, without the increase of production.

\section{Deterioration and corruption of products}

Deterioration and corruption of products is a phenomenon occurring after the production activities of the firm, but since before delivery, production is a part of firm's properties; therefore, this subject is considered in production discussion. Although this deficiency can be a cause of subsequent services such as transport and distribution, but negligence and weakness of sell and operation management may cause this type of corruptions. Usually, products are kept in warehouses before they are distributed and finally consumed. Keeping products may cause deterioration and corruption of products. This is true about perishable goods, as well as imperishable goods. For example, rustiness and corrosion because of humidity and dampness or acidity will deteriorate even metals. Certainly, deterioration and corruption of products apparently are the product losing and from the production point of view means losing production resources, including factors of production used to produce these products. On this basis, we can generalize all arguments regarding squandering in equations (42) and (43) which say the corruption of products causes to use more factors of production without increasing productivity.

\section{Knowledge-based economics and ethic economics}

Knowledge-based economics will affect economic behavior of human being community severely. Passing from traditional economic behavior to knowledge-based economics has been accompanied by information technology developments. Fast growth and development of information technology $y^{7}$ and communication will have multidimensional effects on the set of economic behaviors, and along with it, consumption patterns and economic behaviors will be changed. In this relation, internet transactions and electronic commerce can lead to consumption increase because of its easiness and efficiency.

\footnotetext{
7 - For example, the speed of microchips double every I8 months without any change in price, and the communication bandwidths triple every 12 months, and the worth of a network is proportional with square of its nodes, so that by expansion of the network, the communication value increases exponentially while its cost is constant. (Narrated from: Jalaly, Aliakbar, "The relationship of electronic commerce and knowledgebased Economy", Collection of papers in Electronic Commerce Gathering. http://www.hiberd.com/essay-hiberd/documents-hiberd/03.doc
} 
In a knowledge-based economy, production, distribution, and the use of knowledge and information has an important role in economic activities. The relationship of knowledge-based economy and advanced technology of communication and financial payment services is one of the important factors in change of the form of producer's and consumer's behavior and even the change of production function (because of production technology change) and the form of subordinate utility function of consumer (because of changes in taste and style of his preference ordering). This is because the knowledge element has gained importance in the content of products and services as value and therefore, information and communication technology affecting all factors of production and all manufacturing goods and production processes have led consumption pattern towards variety and mass production and consumption ${ }^{8}$.

Regarding the knowledge-based economy observations, the above analysis is not abolished but even has increased the importance of ethic economics view. This is because the knowledge-based economy changes and acutes economic behavior by increasing efficiency and productivity and easing activities. Developments of information and communication technology principally affect the above analysis from the following aspects:

- Transaction of goods via the internet and other electronic methods

- Easy access to markets, customers, sellers, and intermediates all day long and all weekdays

- No need to direct presence and communication

- Reduction of payment costs by electronic systems

- Decrease of the transaction, warehousing, and distribution costs

- The decrease in intermediate's cost

- The decrease in overhead costs

- Increase in the speed of transaction and delivery

- Ease of advertisement and introducing goods

- Increase of efficiency of advertisement for persuading consumption by applying absorbing tools of advertisement such as color, sound, and presentation

- Decrease of mistakes in comparison with traditional methods of transaction

- Easy access to large global markets

- Continuous presence all over the world

- Update market information

- More transparency of market information

- Variety of goods and services

- Creation of new financial innovations

These developments affect consumer and producer behavior through the following:

- Changing the form of production function because of production technological changes and thereof, substituting capital intensive factors of production with higher yields and more expert and specialist manpower. In addition, the increase of free financial balances of firms because of the decrease of side costs of sale and distribution and thereof, the sale increase.

- Changing the form of consumer utility function because of changes of taste and introducing new goods and changes of consumer priorities, which results in the omission of purchase and transaction costs and the increase in the purchase of other goods because of substitution effect resulted from savings in transaction costs and...

\section{Summary and conclusion}

Ethic economics, as a subject which has received less attention in new economic theories is one of the important subjects which can have considerable effects on the way of life of human beings. Squandering with the meaning of wasting of resources is against maximizing the utilization of resources in economics. According to the neoclassic theory of consumer behavior, this behavior is based upon assumptions, and in the subject of squandering in ethic economics, in addition to neoclassic theory assumptions on consumer behavior, assumptions such as non-satiation assumption can be breached. According to neoclassic theory, people desire to maximize their consumption, considering their priorities between work and leisure time, but practically, consumption utility exceeds the utility of leisure time.

Squandering of resources is a kind of resource wasting, but the term squandering has a more general meaning which includes excessive usage in every kind of affairs, while waste does not have this variety of meaning. Squandering causes waste of some

8 - Refer to: Knowledge Economy Forum III, The World Bank and the Government of Hungary, Improving Competitiveness Through a Knowledge-Based Economy, Budapest, March 23-26, 2004. 
resources by wasting and corrosion, throwing away because of "purchasing greed", or "imitating consumption pattern", or "keeping up with Jones family consumption pattern" or "consumptionism", or "habitual consumption", or generally, "consumerism". In this paper, we showed that consumer loses a part of his utility because of squandering and has to work more and decrease his leisure time to obtain more income for compensating his squandering to regain his lost utility. Briefly speaking, squandering wastes leisure time and the utility obtained from her leisure time.

Evidence of squandering in producer behavior and the production process were also studied. For different reasons, the production line can waste and spoil raw material, intermediate or final goods, or produce commodities at a higher cost and with excessive use of factors of production. That is to say, the main part of squandering in production is the result of inefficient use of factors of production. Evidence of squandering of production are in total productivity, the non-optimal combination of factors of production, damages and spoil and corrosion in production.

Passing from the traditional economy to a knowledge-based economy is accompanied by outstanding information and communication technology. Rapid growth and development of information and communication technology will have multidimensional effects on economic behaviors, and consumption patterns and economic behaviors will change. The above analysis will be completed by knowledge-based economy considerations which regard consumption patterns and economic behavior from different aspects when efficiency improves, and operations become easier.

Altogether, squandering in a society in markets equilibrium in the economy will cause the following:

- More goods will be consumed, without increasing utility

- Demand for goods and prices will increase

- Leisure time will decrease

- Fewer products are produced

- More labor force will be used

- More factors of production will be used in production

- Demand for factors of production and wage will increase

- Efficiency decreases

- Social welfare decreases

In this paper, we conclude that if lessons of ethic economics in forming consumption pattern is strengthened, we can guide economic behaviors towards moderate consumption behavior. If ethic teachings do not carry out this process, people will become as like as the instruments of production and consumption. And in the course of development of humanities will not reach to what he has been created for which is much valuable than material production and consumption. In other words, if the economic behavior of people were not trained, the traditional economy will pull people towards changing them into a machine for "just production-just consumption".

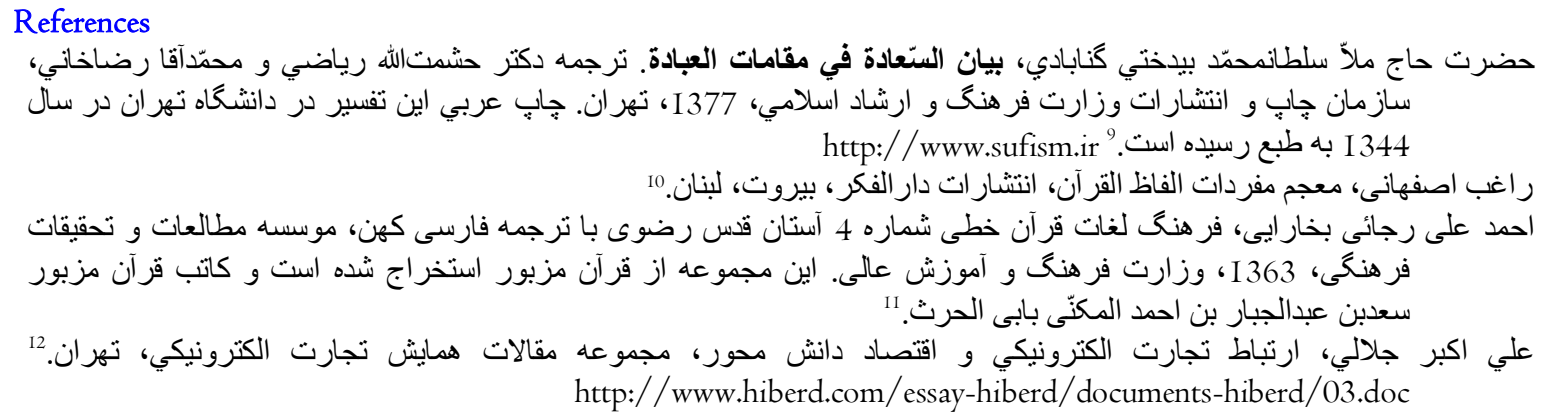

9 - His Excellency Hajj Sultan Mohammad Bidokhti Gonabadi, "Bayan Alsaadah Fi Maghamat Alebadat”, translated by Dr. Riazi, Heshmat Allah and Aghakhani, Mohammad Agha, Rezakhani, Ministry of Islamic Culture and Guidance, Tehran, 1998. The Arabic version of this book was published by Tehran University in 1965.

I0 - Isphahani, Ragheb, "Moajam Mofradat Alfaz Al Quran, Darulfekr, Beirut, Lebanon.

${ }^{11}$ - Rajaee Bokharaee, Ahmad Ali, Dictionary of Words of hand-written script No. 4 of Astan-e- Ghods-e- Razavi with ancient Persian translation, Ministry of Islamic Culture and Guidance, 1984, Tehran. The hand writer of this Quran is Saade-ibn-e-Abdaljabbare-ibn-eAhmad Almokanni Be-Abi Alharath.

I2 - Jalali, Ali Akbar, "The relationship of electronic commerce and knowledge-based economy, collection of papers presented at Electronic Commerce Gathering in Tehran. 
James M. Henderson, Richard E. Quandt (1980), Microeconomic theory, a mathematical approach, $3^{\text {rd }}$ edition, McGraw-Hill Book Company.

R. Blundell (I99I), Consumer behavior: Theory and empirical evidence - A survey. In surveys in economics, edited by Andrew J. Oswald, vol. 2. The Royal economic society, Blackwell, Britain.

C. E. Ferguson, J. P. Gould, (I975), Microeconomic theory, Richard D. Irwin Inc. The United States.

Knowledge Economy Forum III, The World Bank and the Government of Hungary, Improving Competitiveness Through a Knowledge-Based Economy, Budapest, March 23-26, 2004.

Samuel Strauss (I870-1953) Critics on consumptionism. The Atlantic Monthly, Nov. I924.

\section{Copyrights}

Copyright for this article is retained by the author(s), with first publication rights granted to the journal. This is an open-access article distributed under the terms and conditions of the Creative Commons Attribution license (http://creativecommons.org/licenses/by/4.0/). 